(C) Blackwell Publishers Ltd. 1999, 108 Cowley Road, Oxford OX4 1JF, UK and 350 Main Street, Malden, MA 02148, USA.

Ratio (new series) XII 4 December 1999 0034-0006

\title{
NORMATIVE FORCE AND NORMATIVE FREEDOM: HUME AND KANT, BUT NOT HUME VERSUS KANT
}

\section{Peter Railton}

\begin{abstract}
Our notion of normativity appears to combine, in a way difficult to understand but seemingly familiar from experience, elements of force and freedom. On the one hand, a normative claim is thought to have a kind of compelling authority; on the other hand, if our respecting it is to be an appropriate species of respect, it must not be coerced, automatic, or trivially guaranteed by definition. Both Hume and Kant, I argue, looked to aesthetic experience as a convincing example exhibiting this marriage of force and freedom, as well as showing how our judgment can come to be properly attuned to the features that constitute value. This image of attunement carries over into their respective accounts of moral judgment. The seemingly radical difference between their moral theories may be traceable not to a different conception of normativity, but to a difference in their empirical psychological theories - a difference we can readily spot in their accounts of aesthetics.
\end{abstract}

\section{Introduction}

'Normativity' is, for better or worse, the chief term we philosophers seem to have settled upon for discussing some central but deeply puzzling phenomena of human life. We use it to mark a distinction, not between the good and the bad (or between the right and the wrong, the correct and the incorrect), but rather between the good-or-bad (or right-or-wrong, . . .), on the one hand, and the actual, possible, or usual, on the other. Ethics, aesthetics, epistemology, rationality, semantics - all these areas of philosophical inquiry draw us into a discussion of normativity. And they do so not because we philosophers import this notion into our inquiries, but because - sometimes rather belatedly - we discover it there whether we went looking for it or not.

I said 'for better or worse' because, while it is useful to bring these various normative phenomena together, the term 'normativity' itself bears the stamp of but one aspect of such phenomena: 
norms - rules or standards. The etymology of the English term norm traces it back to the Latin norma, a builder's square. The term rule also seems to come to us from the building trade - it descends from the Latin regulus, a straight-edge or ruler. Now anyone who has sawn a board or chiseled a stone recognizes what it is to take a square or a ruler as a guide in cutting, and thus to treat gaps between the actual cut and the square or ruler to show there is something to be "corrected" in the cut rather than the tool. So we have here a seemingly concrete example of "actionguidingness" and an associated "standard of correctness", different from the merely actual, at work. ${ }^{1}$

Because the norma (or regulus) is a tool whose application is so transparent to us, it can prove a useful example. But there is a danger as well as an aptness in using such a model when we attempt to construct a philosophical account of normativity. A builder can consult his norma to guide himself in making cuts and to judge whether his work "measures up", but does this tool, or any tool, tell him why or when his cuts should measure up to the norma? In most cases it is of course evident why they should, and there certainly is no mystery why the builder's square is ubiquitious in the building trade. But what if an arch is needed, or a compound curve - is it still the case that cuts are always to be made following the norma?

Understanding how a norma or a norm could possess legitimate regulative standing thus also requires us to ask: What is it in general for a rule or standard to apply? There is no special difficulty about saying what it is for a rule to apply in (what we might call) a "formal" sense. A norma can be applied to a cut and we can find the cut to fit or not. But in this sense the norma applies even when we needed to cut a curve. So when do we say a rule applies or is in force in the sense that it is to be followed? Clearly, we have simply re-encountered the question of action-guidingness, now in the form of a distinction between "formal" and (and what we might call) "normative" applicability. If at this point we ask for

Moreover, we have an equally concrete way of illustrating part of what Kant had in mind in insisting that the normative is a priori. A norma (or regulus) has its form "before the fact", giving the builder a "standard of correctness" for the cut, but not staking a claim as to how the cut will in fact be made. His subsequent cutting performance is "guided" but not "predicted" by it, so actual failure on his part to conform to the norma does not impugn or discredit the norma a posteriori. For further discussion of these examples, and their relation to the a priori status of norms and rules, see P. Railton, "A Priori Rules: Wittgenstein on the Normativity of Logic", forthcoming. 
another rule, a "rule of application", the threat of regress emerges at once - for how to distinguish those cases in which the rule of application itself normatively applies among those in which it merely formally applies?

We could block the regress if there were a super-rule (rationality?) that always normatively applies and that directs us regarding the applicability of all other rules. Unfortunately, however, the useful transparency of anything like the norma - or of such familiar examples as rules of a game - is lost once we speak of superrules. For we can intelligibly ask when to use the norma- or when to play a game - and why. But somehow, a super-rule is supposed to prevent such questions about itself from arising. Even as strong a proponent of rules and rationality as Kant seemed able to see the sense of asking what might be "the purpose of nature in attaching reason to our will as its governor" (G 305). ${ }^{2}$ This is a question about the normative applicability of "rules of reason", that is, a question about the source of reason's normative authority.

\section{Normative authority}

Authority is an impressive thing. At least, it is when it works. We speak of rules binding us, or being in force, even when we would rather not comply. This suggests a certain image of what it would be to explain or ground normative authority. But though sheer force is sometimes called upon to enforce norms, but it is not much of a model of the "coercive power" of norms as such. Rousseau noted that "If force compels obedience, there is no need to invoke a duty to obey". ${ }^{3}$ A sufficiently great actual force

2 Herein I will use the following abbreviations in citing work of Immanuel Kant: CJ = Critique of Judgment, trans. by Werner S. Pluhar (Indianapolis: Hackett, 1987); CJm = Critique of Judgment, trans. James Creed Meredith (Oxford: Clarendon, 1952); CPrR = Critique of Practical Reason, trans. by Lewis White Beck (Indianapolis: Bobbs-Merrill, 1956); $\mathrm{CPrRm}=$ Critique of Practical Reason, trans. by Mary Gregor (Cambridge: Cambridge Unviersity Press, 1996); G = Groundwork of the Metaphysics of Morals, trans. by H. J. Paton, 3rd ed. (New York: Harper \& Row, 1956); LoE = Lectures on Ethics, ed. by P. Heath and J. B. Schneewind, trans. by P. Heath (Cambridge: Cambridge University Press, 1997); MM = Metaphysics of Morals, ed. and trans. by Mary Gregor (Cambridge: Cambridge University Press, 1996); OBS = Observations on the Feeling of the Beautiful and Sublime, trans. by John T. Goldthwait (Berkeley: University of California Press, 1960); SRL = "On a Supposed Right to Lie from Philanthropy", in Immanuel Kant: Practical Philosophy, trans. Mary J. Gregor (Cambridge: Cambridge University Press, 1996). All page numbers are to the Academy edition; Academy volume numbers are given only for the Lectures on Ethics.

3 Jean-Jacques Rousseau, The Social Contract, trans. Maurice Cranston (Baltimore: Penguin, 1968), Bk. I, ch. 3, p. 53. 
simply is irresistible. Familiar rules and oughts, even stringent ones, are not like that - we can and do resist them, as Kant noted:

The moral law is holy (inviolable). Man is certainly unholy enough, but humanity in his person must be holy to him. [CPrR 87]

Clearly the must here is not the must of something irresistible the moral law is normatively, not actually, "inviolable". Since an ought is to apply to us even when we fall short, its force (and recognition thereof) must leave that option open. If "guidance by norms" is to play a nontrivial role in the explaining the an individual's or group's behavior, then the normative domain must be a domain of freedom as well as "bindingness".

This need for a "possibility of incorrectness" is often remarked upon in philosophical discussions of normativity, usually in connection with physical or causal possibility. But it is no less important to make room for the logical or conceptual possibility of error. It is sometimes said, for example, that a free agent is by definition guided by rationality or a good will. There is no objection to this kind of definition as such, but it does not capture the sense of 'freedom' we need here.

Consider a more mundane example. Suppose that I have written you a letter and have spelled 'correspondence' correctly, rather than as the often-seen 'correspondance'. You, the reader, aware that my spelling is at best uncertain, remark upon my unexpected success to a colleague and wonder aloud whether it was accident or competence. You are, in effect, assessing two explanations, according to one of which I spelled it with an 'e' by chance, while according to the other I did it on purpose (though perhaps without explicit deliberation) - as a manifestation of my internalization of, and deference to, this particular norm of English spelling. Suppose your friend replies, "No, there simply is no question of why Railton spelled 'correspondence' with an 'e'. Spelling is a normative concept - acts of spelling constitutively involve satisfying the norms of spelling. So he couldn't have spelled the word with an 'a' - to have written 'correspondance' wouldn't have counted as a spelling of 'correspondence' at all."

Now there certainly is a "normative sense" of spelling, according to which 'correspondance' cannot count as a spelling of 'correspondence'. In this sense, it is analytic that spelling is correct, and even losers in spelling bees never spell incorrectly. That's why, though it may sound odd to say so, when we ask why or how 
someone spelled correctly we typically are not using the term in this "normative sense". As you intended your question to your colleague, my spelling 'correspondence' with an 'e' was either a happy accident or a pleasant surprise, not an analytic truth.

If a normative must is to have a distinctive place in the world, then, it cannot be the must either of natural law or of conceptual necessity. Natural law and conceptual necessities are "always at work", even when we're tired, weak-willed, lazy, disobedient, evil, or ignorant. No worry about anyone violating them. But normative guidance requires some contribution on our part, in a domain where freedom in the "non-normative" sense makes some vigilance or effort necessary.

However, having escaped the danger of missing the phenomenon of normative guidance altogether by assimilating it to a kind of unfreedom, we had better be careful not to think of it as simply a matter of free willing. First, many of the attitudes (and associated motives and emotions) basic to normative conduct - attitudes of belief, desire, admiration, regret, approval, anger, and so on - appear not to be wholly within the scope of direct willing. ${ }^{4}$ Kant, for example, distinguishes attitudes of love and reverence (reverentia), which are not directly subject to the will and cannot strictly be objects of duty (MM 401-403), from attitudes that accord to others a respectful observance (observantia) of their rights or goals, which can be required of us as a duty (MM 449, 467-468; compare G 399). ${ }^{5}$ Kant does not conclude that attitudes of the first sort are therefore irrelevant to the domain of normative governance - on the contrary, according to the interpretation to be discussed below, they are to be found at the very bottom of his view, as a source or "basis" of duties (cf. MM 402-403).

Second, even if we restrict attention to those areas of normative governance in which the will seemingly can be effective - in selecting among acts, in regulating the more voluntary attitudes (such as acceptance or acknowledgement), and in shaping indirectly over time the less voluntary attitudes and motives (such as

${ }^{4}$ Perhaps judgments concerning these attitudes are more directly within the scope of will, but it is one thing to form a belief or feel an emotion, and another to form a judgment of it. Although our judgment is supposed to guide our belief, our beliefs might in fact prove recalcitrant. Thus we say: judgment is normative for attitudes like belief or feelings like appreciation. For a seminal discussion of evaluation as normative for attitudes, see Elizabeth Anderson, Value in Ethics and Economics (Cambridge: Harvard University Press, 1993), ch. 2.

I am grateful to Peter Vranas for bringing to my attention this discussion in Kant of reverentia vs. observantia. 
esteem, reverence, or liking) - it seems we cannot capture all of normative guidance with the notion of freely willing. For though the will may guide us, what guides the will? If we say, simply, "We do - we exercise our normative freedom and choose", this appears to get at only half the truth. For what makes an exercise of will a choice, rather than a mere fiat? And what would make a choice a moral one - or a rational, aesthetic, prudential, or epistemic one? Could the bare fact that a will is my will make it (say) a good will?

\section{Reason and normativity}

Kant tells us that reason's "highest practical function" is to enable us to discover and "establish" the good will (G 396), but speaking of reason and rationality can be ambiguous, at least in ordinary discourse. Let us distinguish, roughly, two senses of 'rational choice'.

In the first sense, a rational choice is a well-reasoned choice, one that is (or, perhaps, could in principle be) supported by a chain of deliberation in accord with norms of good reasoning. In the second sense, a rational choice is a choice appropriately responsive to reasons, whether or not it is (or, perhaps, even could in principle be) supported by such deliberation.

A simple example might help here. Consider a circumstance in which it would be best to pick an option from among those saliently available, rather than to deliberate - perhaps time is short, or perhaps the question is of little significance. To be "appropriately responsive to reasons" would involve prompt and decisive selection of one option and moving on. If we were even to stop and deliberate about whether to deliberate, we might miss our chance, or waste valuable time. In such cases, the two senses of 'rational choice' come apart in practice.

Yet we might hold that this represents no deep ambiguity in our basic thinking about practical rationality. For it seems we could, in principle, in a restrospective "context of justification", give a well-reasoned argument in favor of selecting without deliberation in certain circumstances. Indeed, it is not uncommon to find philosophers supposing that the two senses of 'rational choice' always come to the same thing, at least once we understand "well-reasoned" in terms of an in-principle constructable argument in the context of justification rather than a piece of actual cogitation in heat of the moment. And in this coming 
together of "well-reasoned" and "responsive to reasons" we might hope to find the secret to explaining how the free and forceful elements of normativity can be combined. Perhaps we can understand normative force on the model of appreciating the force of argument.

The force of argument has many features that make it an appealing general model for normative guidance. Unlike an irresistible coercive or natural force, the force of argument is one we can fail to follow. We have all departed from laws of logic by reasoning fallaciously, and we have all had the experience of finding our actual belief tendencies somewhat recalcitrant in the face of an argument whose validity and premises we cannot fault. The connection between the force of argument and belief is a normative one, rather than a matter of nomic or conceptual necessity.

At the same time, our response to the force of argument seems appropriately free without being arbitrarily willful. When we feel "trapped" by an argument or "caught" in a contradiction, we want out, but we are not inclined to think that we can, with sufficient power of will or strength of desire, bend the logical relations and escape. Moreover, even though logical relations thus stand independent of our will and wishes, recognition of them does not seem to be at odds with our capacity for autonomy in thought and belief. Since we take our beliefs to aim at truth and to be responsive to logic and evidence - one might even say this sort of commitment is constitutive of belief as an attitude ${ }^{6}-$ we do not need to be subject to some further coercion or external sanction in order for self-acknowledged logical implications to be felt as putting normative pressure on us. We think we can see responsiveness to argument as a form of epistemic attunement of just the sort belief presents itself as having - attunement to content, to relations of implication and evidence, and so on.

"The force of argument" is indeed a central example of the peculiar mixture of force and freedom that we take normative guidance to involve. If it were possible to understand all normative guidance on this model, then we might hope that the two senses of 'rational choice' would never lead to genuinely divided

${ }^{6}$ For discussion, see David Velleman, "The Guise of the Good," Nous 26 (1992): 326, and "On the Possibility of Practical Reason", Ethics 106 (1996): 694-726; also, P. Railton, "On the Hypothetical and Non-Hypothetical in Reasoning about Belief and Action", in G. Cullity and B. Gaut (eds.), Ethics and Practical Reason (Oxford: Clarendon, 1997). 
loyalty and that we had gotten to the bottom of things normative. No doubt the lasting appeal of rationalism in philosophy is partly explained by this.

But I will spend most of the balance of this paper discussing in a very preliminary way - some ways in which the force of argument seems unable to afford a general model of normative guidance, or to take us to the bottom of all things normative. I will look first at what might seem the most hospitable territory for the force of argument: epistemology, or reasons for belief. Second, I will look at another domain of judgment, which might at first strike us as peripheral but instead emerges as central: aesthetics. Third, I will consider the classic turf for normativity: morality.

\section{Normative authority for belief}

We face a problem at the very outset attempting to understand normative authority in the domains of theoretical or practical reason in terms of the force of argument. For arguments and the logical relations they involve operate on, and conclude in, propositions. But according to a long tradition that seems worth maintaining, the conclusion of a piece of practical reasoning is an action and the conclusion of a piece of theoretical reasoning is a belief, and neither a belief nor an action is a proposition. If we are somehow to connect the propositional conclusion of an argument to a phenomenon like belief or action, it seems as if some non-argumentative but nonetheless justifying or "rationalizing" relationship must be found. Can we do this without already introducing a species of normative authorization not encompassed by the power of argument?

This is a contested matter. For example, we are inclined to speak of sensory experience as paradigmatically justifying perceptual belief, yet it is far from obvious that the content of experience itself is propositional, or that the justificatory relationship of this content to perceptual belief can fully be captured in deductive or inductive relations among propositions. To explore these questions would take us into deep waters. But perhaps we can give a less controversial example of justified belief to illustrate how difficult it would be to reconstruct all epistemic justification propositionally.

So as not to prejudice matters against "propositionalism", let us make some favorable assumptions. Suppose that we were able to give an uncontroversial account of "the force of argument" in 
the inductive case, that is, of what it is for a hypothesis to be inductively supported to a certain degree by a given body of evidence. And suppose as well that we can state the "rationalizing" relationship linking justified belief to inductive argument by a simple formula: a belief that $h$ of strength $r$ is justified in epistemic context $C$ if $h$ is inductively supported in $C$ to degree $r$.

Focus now on beliefs that ascribe self-identity. Some such beliefs, I trust, are in fact epistemically justified. Can we give an account of this justification in propositional terms, even under our favorable assumptions? Perhaps, one might suppose, they are justified on the basis of an inductive inference from certain coherences and continuities among one's experiences. Consider an argument of the form:

(SI) I have experience e1 at t-3

I have experience e 2 at $\mathrm{t}-2$.

I have experience e 3 at $\mathrm{t}-1$.

I have experience $\mathrm{e} 4$ at $\mathrm{t}$.

Experiences e1-e4 exhibit coherence and continuity.

I therefore conclude (with strength $r$ ) that I am selfidentically me throughout the time interval ( $t-3)$ to $t$.

Yet it is clear that this argument simply presupposes self-identity, since it is formulated in terms of (a presumably unequivocating) first-personal 'I'. Now propositions are essentially third-personal, so we would have to reformulate the argument replacing 'I' and 'me' with 'Peter Railton'. Suppose this done, and suppose there is no doubt about the truth of the premises or the argument's inductive legitimacy. We now have a conclusion about Peter Railton, but it tells me nothing yet about my identity. That is, it does not yet sustain a conclusion licensing a de se self-identity ascription on my part. ${ }^{7}$ It does not tell me that 'Peter Railton' refers to me.

If experiential induction, propositionally construed, will not suffice, where does my sense of self-identity and my entitlement (if any) to the first-personal 'I' come from? Presumably I arrive at a sense of being me (and here, and now) in part from something like what has been called proprioceptive aspects of my experience (both conscious and nonconscious) - a kind of feeling or expectation that pervades my mental life and which, so far as I can see, cannot in principle be rendered as a third-personal

See David Lewis, "Attitudes De Dicto and De Se", in his Philosophical Papers, vol. I (New York: Oxford University Press, 1983). 
propositional content. ${ }^{8}$ Now, if we dismiss this as no more than my "sense" of self-identity, and insist that we would need evidence reconstructable in argumentative form in order to warrant such a conclusion, we will find ourselves cut off from any possible avenue of justification. This could leave us stranded as theoretical reasoners, since without any entitlement to the 'I', how am I ever to be responsive in my belief to the evidence $I$ have? - A lot of people have a lot of evidence, much of it conflicting, but whose should weigh with me? To justify my beliefs I need to identify myself in the space of epistemic reasons.

Hume himself seems to have become sensible of such a defect in any purely continuity-and-coherence-based approach to personal identity, such as the one he experimented with in the Treatise. He reflected in an Appendix:

If perceptions are distinct existences, they form a whole only by being connected together. But no connexions among distinct existences are ever discoverable by human understanding. We only feel a connexion or determination of the thought ... the ideas are felt to be connected together, and naturally introduce each other. [T 635 $]^{9}$

$\mathrm{He}$ is at a loss to describe this feeling, or to explain it as based upon principles. "[T] his difficulty," he concedes, "is too hard for my understanding" [T 636].

Just what a fix we could end up in is seen at the end of Part I of the Treatise, where Hume gives a perhaps inadvertent intimation of the problem his later reflection brought clearly into focus.

8 There is some experimental evidence in the literature on autism that autistic individuals may experience deficits in developing a feeling for the self, much as individuals can experience color deficits in ordinary perception. Autistic individuals, for example, experience difficulty with first- vs. third-person asymmetries in so-called "false belief tasks", and are known to lose track of first- and second-personal pronouns in conversations, as in the phenomenon of "echo-locution". After reviewing a description of a cognitively very high-functioning autistic individual, Temple Grandin, who herself professes finding ordinary social language and exchange baffling, but technical or scientific language much clearer, Simon Baron-Cohen writes:

And her own explanation ... ? "She surmises that her mind is lacking in some of the

'subjectivity,' the inwardness, that others seem to have.

From Mindblindness (Cambridge: MIT Press, 1995), pp. 142-143.

9 Here are the abbreviations used in the text for Hume's writings: Inq = Inquiry Concerning the Principles of Morals, ed. by C. W. Hendel (Indianapolis: Bobbs-Merrill, 1957); $\mathrm{T}=$ Treatise of Human Nature, ed. by L. A. Selby-Bigge (Oxford: Oxford University Press, 1888); ST = "Of the Standard of Taste", in Of the Standard of Taste and Other Essays by David Hume, ed. by John W. Lenz (Indianapolis: Bobbs-Merrill, 1965). 
Hume is describing the depths of the mental distress he reaches as a result of an "intense" commitment to following the rationalistic maxim to restrict belief to those matters where we can give a reasoned justification. He finds that, as a result, he loses any entitlement to confidence in induction, memory, external body, or even deduction. Eventually he "can look upon no opinion even as more probable or likely than another", and calls out in desperation, "Where I am I, or what?" (T 269). Rigorous adherence to the self-imposed rationalist maxim prevents him from attibuting any epistemic authority to his "natural introduction" to the self via an unreasoned "feeling" of it - and he thus loses his grip on self-location and self-identity.

Having seen what it would be to reach this point, Hume cannot convince himself that epistemology would be well-served by unqualified obedience to the rationalistic maxim. Why is it, he wonders, that

... I must torture my brain . . . at the very time I cannot satisfy myself concerning the reasonableness of so painful an application, nor have any tolerable prospect of arriving by its means at truth or certainty? Under what obligation do I lie . . . ? [T 270]

Hume remains concerned with reasonableness, truth, and probability. He is, however, "sceptical" that trusting only the force of argument will enable us to be fully responsive to these concerns.

... understanding, when it acts alone, and according to its most general principles, entirely subverts itself, and leaves not the lowest degree of evidence in any proposition, either in philosophy or in common life. ... I am ready to reject all belief and reasoning .... Whose favor shall I court, and whose anger must I dread? What beings surround me? and on whom have I any influence, or who have any influence on me? I am confounded ... a and begin to fancy myself . . . utterly depriv'd of the use of every member and faculty. [T 268-269]

Far from consolidating belief around a core of rational certainty like the Cartesian cogito, Hume finds himself in a complete collapse of normative epistemic guidance - there remains no discernment concerning evidence or probability, no sense of anyone's authority, even one's own. His "distribution of credence" has become entirely undiscriminating, even with respect to logi- 
cal relations and "the force of argument". How, for example, are we to reason in the "context of justification" about the relationship between our beliefs and their grounds if we accord immediate experience no prima facie authority to support belief even concerning the content of our own thoughts?

If belief and reasoning are to be resurrected, we will need to authorize ourselves to draw directly upon a wider base of epistemic resources, without asking for reconstructability as argument, even in the context of justification. But what to add? Belief, we've noticed, is not a bare proposition, but an attitude toward propositions. Hume puts it starkly: "belief is nothing but a peculiar feeling, different from the simple conception [of its object]" ( $\mathrm{T}$ 624). If we consider de se belief, Hume's suggestion would seem to be that this attitude is a feeling that is to be regulated (at least in part) by "self-introducing" (we might say "self-intimating") feelings. A feeling regulating a feeling? Hume writes that "belief is more properly an act of the sensitive, than of the cogitative part of our natures" [T 181]. Hume appears to apply this idea well beyond self-identifying belief, stressing the role of feelings in shaping belief concerning external objects, and observing:

Nature has . . . doubtless esteem'd it an affair of too great importance to be trusted to our uncertain reasonings and speculations. [T 187]

But what is such regulation of feeling by feeling like, and, if it cannot be reconstructed as a argument, how can it constitute justification? It seems we will need to supplement the normative "force of argument" in epistemology with something like a normative "force of feeling", if we are to resuscitate epistemic discrimination or even self-discernment. How can feeling be appropriately discerning to possess epistemic authority? To have some idea of how this might go, we will turn to another work of Hume's - on discerning, knowing, appreciative feelings.

\section{Normative authority and appreciation}

We encounter a structurally similar problem - of how to find the resources necessary to support a domain of appropriate discrimination in judgment - in Hume's late essay, "Of the Standard of Taste", which apparently is a survival of a systematic project he had undertaken on the nature of "criticism", to include morality 
as well. ${ }^{10}$ After observing that we cannot ground aesthetic distinctions on "reasonings a prior" (ST 231), he begins to consider the possible contribution of sentiment. Yet he quickly finds that mere acquiescence in sentiment would equally leave aesthetic distinctions groundless:

There is a species of philosophy, which cuts off all hopes of success in such an attempt, and represents the impossibility of ever attaining any standard of taste. The difference, it is said, is very wide between judgment and sentiment. All sentiment is right; because sentiment has a reference to nothing beyond itself ...... [E] very individual [therefore] ought to acquiesce in his own sentiment, without pretending to regulate those of others. ... [And thus it is] fruitless to dispute concerning tastes. [ST 230]

This species of philosophy has the wholly "sceptical" result that we cannot even say that Milton is better than Ogilby, and any such philosophy effectively undermines the discrimination upon which taste must be based. Agreeable as this "levelling" sort of skepticism may be to some strands of common sense, common sense on the whole, Hume notes, does not really take it to heart:

Whoever would assert an equality of genius and elegance between OGILBY and MILTON, or BUNYAN and ADDISON, would be thought to defend no less an extravagance, than if we had maintained a mole-hill to be as high as TENERIFE, or a pond as extensive as the ocean. Though there may be found persons, who give preference to the former authors; no one pays attention to such a taste; and we pronounce without scruple the sentiment of these pretended critics to be absurd and ridiculous. [ST 230-231]

Hume isn't personally threatened by a "species of philosophy" that would forced us to give up aesthetic distinctions. "The principle of natural equality of tastes", he believes, can hold sway only in disputatious or esoteric settings where we are not actively relying upon taste to guide us. In ordinary life, it is "totally forgot" (ST 231). Unlike the younger Hume, who wrestled nearly to the point of exhaustion with reason's normative force, worrying

10 See David Fate Norton, "Introduction to Hume's Thought", in his edited collection, The Cambridge Companion to Hume (Cambridge: Cambridge University Press, 1993), p. 27. 
aloud "For my part, I know not what ought to be done" (T 268), the older Hume who wrote "Of the Standard of Taste" seems confident that he knows reason's place and unfraid of the world of normative discrimination tumbling into ruin around him. Any aesthetician - rationalist or sentimentalist - who cannot find a basis for distinguishing a Milton from an Ogilby will simply find himself without authority in Hume's eyes, or ours.

To whose taste, then, do we actually pay some attention, i.e., attribute some normative force, and why would this count as authority about beauty? Hume identifies two sources of authority, convergence of "expert opinion" among those with relevant knowledge and sensory discriminative capacities, and convergence of general, experienced opinion in the "test of time". In both cases, we are seen to accord some authority to these sources, beyond our own simple likings. After all, we know that our own simple likings, convincing though they may be as feelings of attraction, may nonetheless be attributable to our own partiality, ignorance, fashion, novelty, lack of sensory discrimination, or distaste for (or perverse fascination with) the odd or déclassé. Why should this matter - isn't it up to us what we like? Yes, but when we judge beauty, we attribute something to an object or event, not merely to ourselves; and we accord ourselves authority concerning it. Partiality, fashion, lack of sensory discrimination, etc., are all ways in which the pleasure one takes in the experience of a landscape or of a work of art might simply be unrelated to the "beauties" (in Hume's terminology) it possesses - since we do not think self-interest, fashion, and the like are, or "make for", genuine beauty.

Well then, what sorts of features do we uncontroversially take to have a constitutive role in beauty-making, in both natural and man-made objects? Where do we expect to find the "beauties"? Surely, if there is anything at all to our notion of beauty, then among these features are: form, proportion, color, texture, composition, melody, harmony, rhythm, progression, and the like. When these features of an object are of a kind that our sensory and cognitive engagement with them seems reliably to yield experiences we find intrinsically enjoyable, we seem to have (to that extent) a candidate for beauty. That such features do figure in our assessments of beauty is reflected in ways we typically attribute lesser or greater aesthetic authority to our own likings or the likings of others. For example, I do not take my likings concerning Middle Eastern music to have much authority - I am 
inexperienced with it, unable to discern its shades of tonality, structures, progressions, or variety (the different pieces sound too much alike to me), I don't claim to be exercising taste or discernment in when I express sporadic likes and dislikes of what I happen to hear. And I certainly claim no authority over others. By contrast, there are those whose likings in Middle Eastern music I find much more authoritative than mine, and whom I would consult for guidance. Now someone I take to be expert could lose some standing in my eyes if I came to learn that he plays favourites, judges music by its ideological content, lacks sensory discernment, or cannot find other individuals seriously engaged in making or judging such music who take his judgment seriously. Our practices - including our patterns of normative deference - reveal that we do have some idea of what it would be for a feeling (an appreciative delight) to be more or less attuned to objective, beauty-making features of objects, even though this attunement is effected in part via careful cultivation of, and attention to, subjective feelings or sensations.

A degree of deference to experts who possess demonstrable skills of discernment, greater knowledge of genre or context, wider experience, and so on, enables me to extend my "critical" power in detecting beauty-making features - they help me form a better idea of what I'd find delightful were I to gain greater experience. As a result, they help attune me to the "beauties" of objects, features which can be rich and lasting sources of sensorily-based, cognitively-engaging delight. Hume puts it thus:

Those finer emotions of the mind are of a very tender and delicate nature, and require the concurrence of many favourable circumstances to make them play with facility and exactness, according to their general and established principles. The least exterior hindrance to such small springs, or the least internal disorder ... . and we shall be unable to judge of the catholic and universal beauty. The relation, which nature has placed between the form and the sentiment, will at least be more obscure; and it will require greater accuracy to trace and discern it. [ST 232-233]

A similar sort of authority, also related to an authority we already accord ourselves, attaches to the "test of time". Hume writes, concerning the relation "nature has put between form and sentiment" which underlies beauty: 
We shall be able to ascertain its influence not so much from the operation of each particular beauty, as from the durable admiration, which attends those works, that have survived all the caprices of mode and fashion, all the mistakes of ignorance and envy.

The same HOMER, who pleased at ATHENS and ROME two thousand years ago, is still admired at PARIS and at LONDON. All the changes of climate, government, religion, and language, have not been able to obscure his glory. [ST 233]

Long exposure, developed sensibilities, the authority of countless experiences on the part of different individuals - how far we are from my inexperienced self overhearing a snatch of Middle Eastern music at lunch and saying "Hmm, don't care much for that". It is natural to see this as a difference in attunement to musical value.

Over the course of a life, we participate in a complex critical and appreciative practice, attributing some authority to our own growing experience ("In the end, the proof of the pudding ..."), making recommendations and seeking confirmation in the opinions of others ("Try it, you'll see for yourself"), and also showing some deference to various external sources of authority ("After what I've heard about it, I'm eager to try this place"). Situated within such a practice, which extends across societies and times and is held together both by our fundamental human sensory and cognitive similarities and by our reciprocal deferences, my judgments of beauty have at least a chance to be "normed by" the sources of aesthetic value, and words like 'beautiful' in my mouth have a chance of expressing genuinely aesthetic evaluations, even when I get things wrong. ${ }^{11}$ We manage, that is, to have a domain of real distinctions concerning beauty, a domain of genuine taste, even though "subjective feelings" play an essential role in its shape.

Kant was also concerned to underwrite the possibility of objectivity in the domain of taste. Like Hume, he worried about various ways in which appreciation might be attuned or disattuned to genuine value. Kant writes:

11 A common standard of time and shared conventions about when to arrive for (say) a noon engagement make it possible for me to be on time, but also late. In the case of good - and bad - taste, something more than this conventional infrastructure is required, e.g., Hume's account of beauties to be attuned to. 
. . . everyone says: Hunger is the best sauce; [but] to people with a healthy appetite anything is tasty provided it is edible. Hence if people have a liking of this sort, that does not prove that they are selecting by taste. Only when their need has been satisfied can we tell who in a multitude of people has taste and who does not. [CJ 210]

Hunger makes our likings unreliable. But when, for Kant, could a subjective condition such as liking be a reliable guide to a purportedly objective matter, such as aesthetic value?

Kant could not pursue Hume's solution, of looking to the refinement and qualification of empirical faculties and sentiments. Hume's psychology attributes to "the internal frame and constitution of the mind" appetites and passions that are directly aimed at features of the world independent of the self, and are "antecedent" to self-interest or happiness (Inq 113-119). But in Kant's empirical psychology, by contrast, appetites and passions are always guided at base by one's own pleasure:

All the inclinations together (which can be brought into a tolerable system and the satisfaction of which is then called one's happiness) constitute regard for oneself (solipsismus). [CPrRm $73]^{12}$

Within such a psychology, to become ever more delicately attuned to nuance in one's empirical feelings would simply be to become ever more attentive to promoting personal pleasure, regardless of how the pleasure is produced, whether any appreciative or cognitive faculties are engaged, and whatever the nature of the cause of the pleasure. Pleasure and affect are in this sense "blind" for Kant (CJ 272), since "if our sole aim were enjoyment, it would be foolish to be scrupulous about the means of getting it" (CJ 208). An Oriental massage in which the joints and muscles are agreeably "squeezed and bent" would be lumped together with a stirring Greek tragedy (CJ 274).

In aesthetics, we must focus not on which phenomena produce the greatest or most intense pleasure, but rather on the

12 We can see an analogy with the case of theoretical reason. If we thought that all inclination to believe was essentially self-regarding (solipsismus), and attuned to gratification rather than objective conditions, truth, or evidence, then we would find genuine "epistemic worth" only in a dutiful capacity to resist epistemic inclination and regulate belief by epistemic principle alone. This would not make "epistemic dutifulness" into the "highest end" of epistemic activity - that would remain the marriage of justified belief with truth that constitutes knowledge - , but into an indispensable condition of it. 
"presentation" of objects to the senses: we must be able to see the object "as poets do", and "must base our judgment regarding it merely on how we see it" (CJ 270), that is, on the genuinely beauty-making characteristics. Self-oriented and pleasure-seeking, our empirical sentiments are careless as to modality. Kant thus foretold the fate that awaited aesthetics in the hands of that redoubtably thorough-going proponent of egoistic hedonism, Bentham: the only ground of discrimination would be quantity, the "mass of agreeable sensation" (CJ 266) - and pushpin (or Oriental massage) would indeed be deemed as good as poetry.

Moreover, Kant joined Hume in insisting that aesthetic judgments purport to be "non-personal" and communicable to others - in the sense not only of informing others concerning what we like, but of recommending, where each of us purports to have potential authority for others. "But," Kant argues,

if we suppose that our liking for the object consists merely in the object's gratifying us through charm or emotion, then we also must not require anyone else to assent to an aesthetic judgment we make; for that sort of liking each person rightly consults only his private sense. [CJ 278]

For similar reasons, Kant insists that in order to ensure that our account is "concerned solely with aesthetic judgments", "we must not take for our examples such beautiful or sublime objects of nature as presuppose the concept of a purpose" (CJ 269-270). To the extent that the force of an example can be attributed to purpose (e.g., self-interest), the judgment will not be aesthetically attuned - we might substitute for the object of appreciation anything that would bring about the sought-after result equally well.

... the purposiveness would be either teleological, and hence not aesthetic, or else be based on mere sensations of an object (gratification or pain) and hence not merely formal. [CJ 270]

Therefore:

It seems, then, that we must not regard a judgment of taste as egoistic ... we must acknowledge it to be a judgment that is entitled to a claim that everyone else ought also to agree with it. But if that is so, then it must be based on some a priori principle (whether objective or subjective) ... [J]udgments of taste presuppose such a command, because they insist that our liking be connected directly with a presentation. [CJ 278] 
If our judgment is to be attuned to the sources of aesthetic value by a "liking" that is "connected directly with a presentation", but empirical likings cannot do this, where then is taste's infrastructure, where to turn for regulation of our feeling of appreciation - for Kant insists that appreciation, even of the beautiful and the good, is a liking, a feeling (CJ 210)?

Kant looks to reason. The seeming peculiarity of Kant's aesthetic, that it sees aesthetic judgments as "demands of reason", can be understood in this light. But we must be careful, for such demands of reason are not demands based upon argument, rule, or conceptual demonstration:

... the beautiful must not be estimated according to concepts, but by the final mode in which the imagination is attuned so as to accord with the faculty of concepts generally; and so rule and precept are incapable as serving as the requisite subjective standard for that aesthetic and unconditioned finality in fine art which has to make a warranted claim to being bound to please. Rather must such a standard be sought in the element of mere nature of the Subject, which cannot be comprehended under rules or concepts, that is to say, the supersensible substrate of all the Subject's faculties (unattainable by any concept of understanding) .... [CJm 344]

Here, then, we have Kant's version of the subjective attunement that affords reliable guidance concerning the beauty-making features of the world: the pleasure afforded by activity on the part of the self's supersensible substrate, when directly engaging the sensory "presentation" of the object. This substrate, shared as it is by all rational humanity, helps supply the needed infrastructure for a domain of objective taste. Now an invocation of a supersensible substrate may sound like hocus-pocus, but Kant deserves credit for refusing to be false to the "non-personal" compellingness of the experience of aesthetic appreciation, in order to satisfy an allegedly scientific egoistic, hedonist psychology. Not hiding its "unfathomableness", Kant gives the best explanation he can: only the rational self has the requisite formal, disinterested, "nonpersonal", and universal character to be the source of such a pleasure.

But Kant's rational self is not simply a reasoning self. Beauty is a "way of presenting" that requires concepts, yet Kant recognizes that aesthetic appreciation is not simply a matter of being "brought to concepts" (CJ 266). If we were nothing but "pure 
intelligences", "we would not present in this way" and could not see beauty (CJ 270). Nor is the rational self the whole infrastructure. According to Kant, beauty "holds" - presumably, is capable of "norming" judgment through feelings of appreciation and the practice of taste - only for "beings who are animal and yet rational, though it is not enough that they be rational" (CJ 210).$^{13}$

Despite the indispensable role of reason, then, in attuning us to the beautiful, the normative force of judgments of beauty, even for a rationalist aesthetic such as Kant's, is not the force of argument. We therefore cannot expect that we could reconstruct aesthetic justification in propositional terms. As in the case of de se attitudes, an attitude (in this case, aesthetic appreciation) may stand in a justified relationship to its proper object even though this relationship is not mirrored in an argumentative relationship among propositions.

In appreciation we find the right mix of force and freedom for normative guidance. On the one hand, "the liking involved in our taste for the beautiful is disinterested and free" (CJ 210). On the other hand, we all know the compelling character of aesthetic appreciation and good criticism: we find in our first-personal experience of the object, as informed by the contributions of the critic, something both likeable and convincing. "Ah, now I see it," we think, thereby feeling the force of aesthetic authority: a force of credible influence from the critic ("He helped me see it"), of convincing experience from our own case ("Now I get it"), of a compelling work ("There was a lot more in it than I thought"), and of a discovery of value that we can share with others ("You must try this" or "You must read his essay, it'll change how you look at Miró").

Wittgenstein, in his "Lectures on Aesthetics", gives as his model of aesthetic appreciation an example of this process, drawn from his own case: ${ }^{14}$

Take the question: "How should poetry be read? What is the correct way of reading it?" ... I had an experience with the 18th-century poet Klopstock. I found that the way to read him

13 According to Kant, an appreciation of the sublime also depends upon a "way of presenting", and so is not available to a pure intelligence (CJ 270). However, he also believes that our capacity to appreciate the sublime does not depend upon our animal nature. More on the sublime, below.

${ }_{14}$ Ludwig Wittgenstein, "Lectures on Aesthetics", in Cyrill Barrett (ed.), L. Wittgenstein: Lectures and Conversations (Berkeley: University of California Press, 1966). Hereinafter, LA. 
was to stress his metre abnormally. Klopstock put $--\sim$ (etc.) in front of his poems. When I read his poems in this new way, I said, "Ah-ha, now I know why he did this." What had happened? I had read this kind of stuff before and had been moderately bored, but when I read it in this particular way, intensely, I smiled, said "This is grand", etc. But I might not have said anything. The important fact is that I read it again and again ... that I read the poems entirely differently, more intensely, and said to others: "Look! This is how they should be read." [LA, 4-5]

Kant and Hume agree that, underlying aesthetic evaluation, there must be some form of "liking" or "enjoyment". Moreover, the liking in question must be sensorily-based, cognitively-engaging, discerning, disinterested, and communicable. If Hume is right, our essentially similar "internal fabric" - our empirical psychology and sentiments - can afford much of the ground for such a liking, since many of our appetites and passions take external conditions or sensory "forms or qualities" as their immediate objects and are disinterested in character, even though satisfying them will also yield pleasure. Thanks to additional qualification of feeling by the influence of reason, understanding, and the commerce of opinion, we can develop on this psychological "common ground" a domain of discernment and knowledge, where we can recognize and possess authority, and 'beauty' can have its true meaning - apart from fashionableness, novelty, endearing schlock, ponderous "importance", snobbish overrefinement, and so on. In Hume's account, as in Kant's, what possesses ultimate aesthetic authority is a qualified appreciative attitude and not a mere liking. In Hume's account, as in Kant's, much of the qualification of attitude is supplied by reason. And in Hume's account, as in Kant's, it seems we could not reconstruct aesthetic justification in terms of the force of argument. ${ }^{15}$

\section{The normative authority of moral rules}

Perhaps no one is really tempted by the idea that the normative force of aesthetic appreciation rests upon argument. But things might be different in the moral case, where the supremacy of

${ }_{15}$ For further discussion of Hume's aesthetic theory, see P. Railton, "Aesthetic Value, Moral Value, and the Ambitions of Naturalism", in Jerrold Levinson (ed.), Aesthetics and Ethics (Cambridge: Cambridge University Press, 1997). 
reasoning and rules is often invoked. Perhaps in morality at least we will find it possible to account for normative force in terms of the force of argument.

Let us set aside for now a very general worry about this line of thought, briefly touched on in the introduction: any appeal to rules as a foundation for justification runs the risk of regress or circularity unless we can appeal to a super-rule of a mysterious kind. For now let us cheerfully assume that we don't mind mystery, as long as its name is rationality.

Kant's moral philosophy is often taken to be the locus classicus for the idea that normativity resides in rationality itself, and the moral law it prescribes. Perhaps this is indeed how we should understand his view: there is a super-rule, and it commands our obedience as a rational obligation. But is it obvious that this is how he understands his own most basic approach to normativity? We are told to have respect (reverentia) for the moral law, but Kant observes:

Respect (reverentia) is, again, something subjective, a feeling of a special kind, not a judgment about an object that it would be a duty to bring about or promote. For, such a duty, regarded as a duty, could be represented to us only through the respect we have for it. A duty to have respect would thus amount to being put under obligation to duties ... . [MM 402-403]

So it seems we must look for "a feeling of a special kind", not obligation, at the bottom of moral duty. What is this feeling like? Here is an example of the sort of reverential appreciative feeling Kant appears to have in mind:

... to a humble, plain man, in whom I perceive righteousness in a higher degree than I am conscious of in myself, my mind bows whether I choose or not, however high I carry my head that he may not forget my superior position. . . . Respect is a tribute we cannot refuse to pay to merit whether we will or not; we can indeed outwardly withhold it, but we cannot help feeling it inwardly. [CPrR 76-77; compare G 454]

What we perceive in this individual is not simply more severe dutifulness than our own. We are all familiar with individuals who turn sensible everyday rules into severe duties that rise above all inclination, but our mind does not bow to that. ${ }^{16}$ What we perceive,

${ }_{16}$ For a description of dutifulness of this kind, see David Schapiro, Autonomy and Rigid Character (New York: Basic Books, 1981), pp. 83-86. 
according to Kant, is greater righteousness, dutifulness that "includes" a good will (G 397).

In our appreciative encounter with it, we once again encounter the mixture of force and freedom characteristic of normative force. On the one hand, the respect is "freely paid" for Kant, nothing in our experience suggests that any self-interested incentive or external coercion lies behind our appreciation. On the other hand, the respect is in a way compelled, it is something "we cannot help feeling", even when it comes in the face of interest. Kant writes:

Duty! Thou sublime and mighty name that dost embrace nothing charming or insinuating but requirest submission and yet seekest not to move the will by threatening aught that would arouse natural aversion or terror which of itself finds entrance into the mind and yet gains reluctant reverence .... [CPrR 86]

Now this impressive paean might suggest an intrinsic evaluation of duty. But, as Paul Guyer reminds us, ${ }^{17}$ Kant continues, still addressing "Duty":

. . . what origin is there worthy of thee, and where is to be found the root of thy noble descent which proudly rejects all kinship with the inclinations and from which to be descended is the indispensable condition of the only worth which men can give themselves?

It cannot be less than something which elevates man above himself as a part of the world of sense, something which connects him with an order of things which only the understanding can think and which has under it the whole system of all ends which alone is suitable to such unconditional practical laws as the moral. [CPrR 86-87]

Notice that the practical laws of morality, and even duty itself, are not self-subsistent sources of unconditional worth - their worth arises from their "descent", which does secure the noble standing of morality. ${ }^{18}$

At the bottom of morality's normative authority, then, Kant

${ }_{17}$ See Paul Guyer, "Kant's Morality of Law and Morality of Freedom”, in R. M. Dancy (ed.), Kant and Critique (Dordrecht: Kluwer, 1993), p. 70.

${ }_{18}$ Guyer emphasizes the consistency with which Kant, over the course of his philosophical career, recognized that all evaluation presupposes some values-in-their-ownright. The value Guyer identifies is the special freedom Kant attributes to human agents. See his "Kant's Morality of Law and Morality of Freedom". 
speaks not of an analytic demand of consistency nor a willful exercise of our capacity to govern ourselves by rules, but of an experienced synthetic demand and a free acknowledgement, the subjective expression of which is a feeling of a more aesthetic character, akin to the demand upon us that the appreciation for the sublime in nature involves:

It is in fact difficult to think of a feeling for the sublime in nature without connecting it with a mental attunement similar to that for moral feeling. [CJ 128]

For Kant, as we saw in the aesthetic case, human inclination and appetite cannot attune us to this sort of demand, because they are by nature self-interested ("solipsismus", CPrR 73) rather than non-personal and distinterested, and thus "human nature does not of itself harmonize with the good" (CJ 271). Kant therefore must find a faculty internal to us, capable of evincing or guiding a special sort of liking, a "moral feeling", that is attuned to the moral-value-making features of the world, the sources of moral worth. We can, he writes, be attuned to the good "only through the dominance that reason exerts over sensibility" (CJ 271). So, as in aesthetics, to underwrite a rational demand as grounded in the right sort of attunement, we must have recourse to a "supersensible substrate", a noumenal self. Moral judgments are akin to aesthetic judgments of sublimity - judgments of beauty draw in part upon our "animal" nature; for the moral and the sublime, reason alone, the "supersensible substrate", suffices.

Now for Hume, the "substrate" for moral and aesthetic judgment can be our empirical psychology, since it contains sentiments of a suitably "impersonal" and non-self-interested nature. For example,

We are certain, that sympathy is a very powerful principle in human nature. We are also certain, that it has a great influence on the sense of beauty, when we regard external objects, as well as when we judge of morals. We find, that it has force sufficient to give us the strongest sentiments of approbation . . . [T $618]^{19}$

Thanks to sympathy, among other sentiments, our sentiment of

19 A more contemporary psychological account would notice that Hume's sympathy involves two elements: empathy (a direct internal simulation of the circumstances and mental states of others) and sympathy (a direct positive concern for their well-being). 
direct approval can be attuned to the ends of others as such, and to the general interest, even when we have no personal interest at stake: reading ancient history, we wince at a tyrant's cruelty, and root for the hero to save the populace from him. And much aesthetic judgment, likewise, depends upon a capacity to feel the feelings of others. If well-developed, well-informed, and attentively listened to, such "impersonal" sentiments can attune us to - "harmonize" us with - the good and the beautiful.

We may observe, that all the circumstances requisite for [sympathy's] operation are found in most of the virtues; which have, for the most part, a tendency to the good of society, or to that of the person possess'd of them. [T 618]

Sympathy can of course be misled, and may lead us astray. It may fail to be engaged in unfamiliar or misunderstood surroundings. Or it may immediately attune us to the evident pain of animal undergoing an emergency veterinary procedure, making us wish fervently that the procedure would stop, even though this operation is necessary for the animal's survival. Sympathy - like aesthetic admiration - therefore must be assisted and qualified by knowledge, understanding of cause and effect, and reason, and by participation in a community in which our judgments may be challenged and improved if (as we tend to do) we launch our opinions into the public world and also to defer to some degree to the judgments of others and to social practices hammered into shape over the generations. Thus - once again, as in the aesthetic case - our feelings can develop greater freedom from prejudice, finer discrimination, and closer attunement to genuine moral distinctions.

By contrast Kant, as an egoistic hedonist in psychology but a universal humanist in morality, could no more entrust moral attunement to "solipsistic" empirical sentiment (cf. CPrR 73) than he could aesthetic attunement. ${ }^{20}$ And thus we arrive at Kant's answer to the question why nature attached reason to will (which

20 Contemporary empirical psychology on emotion, motivation, and moral development tends to favor a more Humean view. See for example, J. H. Barkow, L. Cosmides, and J. Tooby (eds.), The Adapted Mind (New York: Oxford University Press, 1992); BaronCohen, Mindblindness; Antonio Damasio, Descartes' Error (New York: Putnam, 1994); N. Eisenberg and J. Strayer (eds.), Empathy and its Development (Cambridge: Cambridge University Press, 1987); N. Eisenberg and P. Mussen (eds.), The Roots of Prosocial Behavior in Children (Cambridge: Cambridge University Press, 1989); Joseph LeDoux, The Emotional Brain (New York: Simon \& Schuster, 1996); L. May, M. Friedman, and A. Clark (eds.), Mind and Morals (Cambridge: MIT Press, 1996); and David G. Myers, The Pursuit of 
is, for Kant, also a liking; CJ 209): without the "substrate" of reason to ground impersonal feelings, we would arrive only at a personalistic willfulness, not a good (i.e., general) will. Hume gave us a story as to how the empirical, psychological "substrate" we share as humans generates likings that can be attuned to beauty and the general good. What mechanism does Kant give to explain how a "supersensible substrate" can function similarly? Here Kant is, as befits his penetration as a philosopher, entirely frank: he has no positive idea - the matter involves an "unfathomable depth of [a] supersensible power" (CJ 270; G ).

Note, however, that Kant is also clear that reason cannot operate here by argument alone:

. . . when in intuiting nature we expand our empirical power of presentation (mathematically or dynamically [a "might over the mind"]), then reason, the ability to [think] an independent and absolute totality, never fails to step in and arouse the mind to an effort, although a futile one ...... [W] e are compelled to subjectively think nature itself in its totality as the exhibition of something supersensible, without our being able to bring this exhibition about objectively.

... We cannot determine this idea of the supersensible any further, and hence cannot cognize but can only think nature as an exhibition of it. . . This judging strains the imagination because it is based on a feeling that the mind has a vocation that wholly transcends the domain of nature (namely, moral feeling), and it is with regard to this feeling that we judge the presentation of the object subjectively purposive. [CJ 268]

Our mind, in its "supersensible vocation", is here functioning in a way Hume would have recognized despite the heavily Kantian language: feeling and imagination are regulating judgment, beyond the scope of cognition and argument alone. Within this scheme, as within Hume's, we may use arguments to help us attain or correct a moral feeling or sentiment. For Kant, the "contradiction in conception" and "contradiction in will" tests of our practical maxims can place a purportedly good will face-toface with its potential own limitations, deflating or affirming its

Happiness (New York: William Morrow, 1992). Empathy has been credited in some historical cases with greater efficacy than principles in inhibiting compliance with cruelty commanded by authority. See Roy F. Baumeister, Evil: Inside Human Violence and Cruelty (New York: W.H. Freeman, 1997). 
self-representation as perfectly general. For Hume, understanding and general rules help to extend or correct untutored sympathy.

If reason's functioning as a supersensible substrate for feeling remains for Kant something of which he cannot give a positive account, he nonetheless believes we can convince ourselves of its possibility: we know from first-hand experience the "striking down" of our pretenses and humiliating acknowledgement of our own limitations, and we also know that reason alone among our faculties possesses the qualities necessary for such experience - it alone can furnish guidance that is impersonal. There is no mystery about this when we confront the sublime in nature or morality. The peculiar awe we experience when we come upon "a mountain whose snow-covered peak rises above the clouds" (OBS 47 ) or when we observe an act of genuine duty performed in spite of conditions of extreme "subjective limitation", has extraordinary power to move us, yet cannot be attributed to empirical sentiment. We find our own self-conceit "humiliated" or "struck down" (CPrR 73) in the presence of the sublime. Fortunately, we are not merely flattened. Instead, we are awakened to a value "beyond price", carried beyond ourselves for the moment to sense a "direct liking", a liking even of that which strikes at the very heart of our own prideful self-interest. Thus it recruits our fundamental allegiance, despite any personal interest to the contrary.

To behold virtue in her proper shape is nothing other than to show morality stripped of all admixture with the sensuous and of all the spurious adornments of reward or self-love. How much she then casts into the shade all else that appears attractive to the inclinations can be readily perceived by every man if he will exert his reason in the slightest . . . [G 61-62n]

No wonder such a "presentation" moves us, and yields not the "cold and lifeless approval, without any moving force or emotion" (CJ 273, 274) that we would otherwise expect from any merely un-self-interested presentation. Confronted with the sublime, we are not tempted to think, "Yeah, but what's it to me?" No wonder such a "presentation" is regulative for our wills when we are rational, i.e., attuned via our "supersensible substrate".

This has an important implication for our normative life together: since it owes nothing to personal interest, our sense of the sublime in nature and in conduct should be "subjectively" 
confirmable by other rational beings in their own experience. Others, too, Kant is confident, will stand in awe before the Alps during a storm or find that their mind bows when observing a humble person doing his duty in the face of great temptation. Our moral understanding, like our aesthetic understanding, will be communicable to others in the form of a recommendation, and it will afford a compelling ground for life together that conflicting individual interests do not. The compulsion here is not at bottom that of will, or law, or rule, or consistency. Instead, it is a kind of liking that is free but not simply chosen, and that is regulative for action. It is, then, our attitude when we are "mentally attuned" by reason, and no mere submission - even though we precisely recognize that it is not simply up to us what we make of it. This is the experience of normative authority.

\section{The rule-breaking considerations}

Duty belongs to a family of rule- or consistency-based notions. And indeed we typically assume that morally good conduct will follow rules and exhibit consistency. But if Kant is right, then behind these rules - exceptionless, in his system - lies something quite different: a kind of direct liking akin to the experience of the sublime. We do not have rules "all the way down", but must instead encounter a substantive appreciation of value and associated feelings.

Hume was acutely aware of the potential this affords for conflict. If following "the rules of reason" led always to conclusions that substantive evaluation and feeling also embraced, we'd have no difficulty. But at least in epistemology, Hume finds that following the strictest epistemic duties, to accord epistemic respect ("rational credence", we might say) only to conclusions justifiable by reason alone, leads him to an epistemic condition that he cannot find stably credible or genuinely compelling in the guidance of his overall epistemic life. Might the same be true in the moral case?

Consider Kant's discussion of obedience to a tyrannical ruler.

... a people has a duty to put up with even what is held to be an unbearable abuse of supreme authority [since] its resistance to the highest legislation can never be regarded as other than contrary to law ... . For a people to be authorized to 
resist, there would have to be a public law permitting it to resist, that is, the highest legislation would have to contain a provision that is not the highest and that makes the people, as subject, by one and the same judgment sovereign over him to whom it is subject. This is self-contradictory . . . [MM 320] $]^{21}$

Here Kant appeals to a consideration of consistency to ground a claim of duty. And he has an excellent point, emphasized earlier and in a characteristically different way by Hobbes: a sovereign can benefit us by solving the problem of potentially unending social conflict only if our agreement to obey does not contain a clause reserving to each the right to decide on his own authority when to obey.

Hume, likewise, is aware that "the advantage we reap from government" will be imperilled if each allows himself to regulate his own obedience in accord with his own ideas of what is just or beneficial. The result could only be "endless confusion, and render all government, in a great measure, ineffectual" (T 555). "We must, therefore, proceed by general rules and regulate ourselves by general interests" (T 555). But how is it possible for advantagebased duty to take on a life of its own?

... there is a principle of human nature, which we have frequently taken notice of, that men are mightily addicted to general rules, and that we often carry our maxims beyond those reasons, which first adduc'd us to establish them. . . . It may, therefore, be thought, that in the case of allegiance our moral obligation of duty will not cease, even tho' the natural obligation of interest, which is its cause, has ceas'd . . . . [T 551]

Hume, political conservative that he was, has here a golden opportunity to embrace a Kant-like principle of passive obedience, and even continues "It may be thought that . . . men may be bound by conscience to submit to a tyrannical government" (T 551). But he shrinks from this conclusion:

Those who took up arms against Dionysus or Nero, or Philip the second, have the favour of every reader in the perusal of their history; and nothing but the most violent perversion of common sense can ever lead us to condemn them. 'Tis certain, therefore, that in all our notions of morals we never entertain such an absurdity as that of passive obedience, but make

${ }^{21}$ I am grateful to Tamar Schapiro for bringing this passage to my attention. 
allowances for resistance in the more flagrant instances of tyranny and oppression. [T 552]

How, then, does Hume block the unwanted conclusion of passive obedience? What general rule or practical maxim does he formulate for the citizen to follow to replace the rule of passive obedience? He offers none, only a general suggestion that "the obligation to obedience must cease" when it sufficiently loses its point, that is, "whenever the [common] interest ceases, in any great degree, and in a considerable number of instances" ( $\mathrm{T}$ 553 ).

How, then, is this to work? "The common rule requires submission", but "grievous tyranny and oppression" allows individuals to make "exceptions" (T 554). Here we have a discontinuous change, a departure from own conscientious dispositions to obey which "bind us down", as we rise up in active resistance to government. It looks as if the chief mechanism that awakens us from our "addiction" to general rules is a sympathetic sense of the violation of the general interest. Indeed, sympathy is strong enough that, however much we dislike mayhem and disorder, our approval is excited by rebellions against tyranny of which we hear only in histories or fiction. A morality that would put a people at the mercy of its rulers will not win our wholehearted admiration or esteem. Here we follow no maxim or rule, but a developed sentiment.

It is important to see, however, that the sentiment is developed. Self-love and sympathy alone do not yield any comprehension of when a complex political system is abusive or when such abuses have become too considerable. Justly and unjustly inflicted punishment alike look and feel painful; just and unjust war alike are costly and terrifying. An attunement to the general interest calls for complex awareness of cause and effect, and of long- vs. shortterm, as well as sympathy for victims. Nonetheless, Hume's account is, in the Kantian sense, heteronomous, since it gives sentiments an essential role, and moreover it yields no strict maxim that individual's could legislate for themselves. ${ }^{22}$

22 The difficulty of formulating a decision rule to be used by individuals here may be a difficulty in principle. Whether it makes sense for you to disobey a tyrant, for example, depends upon whether others will disobey, and their reasoning has a similar dependence upon yours. Problems such as this may admit of general criteria for evaluation (such as a standard of the general interest), but no decision rule or maxim that individuals can selflegislate that would satisfy those criteria. For discussion, see Donald Regan, Utilitarianism 
But, stepping back from a model of autonomy as maxim-based self-legislation, if we reflect upon Hume's position on passive obedience vs. Kant's, which of the two, in fact, seems to provide greater practical or political autonomy? Which affords us, as citizens or as moral agents, greater scope to deploy and act on the full range of our human critical faculties?

Suppose Kant were to abandon his egoistic hedonism about human psychology and accept instead the Humean view that sentiments can help attune us to be attuned to legitimate grounds for moral, aesthetic, or epistemic evaluation. Would he still insist that our only hope for genuinely moral, aesthetic, or epistemic conduct - or autonomy - lies in imposing over sentiment a regime of exceptionless rules?

Of course, I cannot answer on Kant's behalf, but I can attempt this: apply Kant's own test of fundamental normative authority, and see where it might lead. How is this possible? Kant's test, recall, involves a special sort of first-personal confirmation: when (for example) we confront the humble man who insists on being honest despite personal costs that we realize would likely overwhelm us, "the mind bows"; when we attend perceptually to sublime scenes in nature, we cannot help but be awed.

Return now to the tyrannical ruler and the obedient citizenry, who accept without resistance all forms of abuse and humiliation. Does "ordinary reason" (G 394) find passive obedience to tyranny sublime - does the mind indeed bow?

I'm willing to bet with Hume that in this case it does not. Impressive as the spectacle may be of passive obedience in the face of great abuse, and powerful as the will must be to restrain an individual feeling the tugs of inclination to strike back at the tyrant, does our mind really bow before this sight? Suppose that the peculiar abuse by government is an order to inform on our friends, to reveal their location to an authority whose plan is to eliminate or torture dissidents or religious minorities. It seems, perhaps, that we know Kant's answer: obey authority; never lie, even to conceal a friend (cf. SRL). And this is the sort

and Cooperation (Oxford: Clarendon, 1980). More generally, significant limitations of decidability and computability arise for any attempt to give individuals non-self-defeating maxims to guide their conduct in collective settings requiring coordination "autonomously" (in the literal sense - each following his or her own rule). 
of example that has often enough been used by critics of Kant as a reductio of his conception of the ground of morality.

But Kant deserves better treatment. Those of us who find in Kant's writings a deep insight into the authority of moral experience should not betray this insight by allowing critics to focus instead on his attempts to apply a multi-layered theory in practice, mediated by a defective empirical psychology. His application may go wrong in cases like "passive obedience", but the fundamentals may yet be sound.

At the fundamental level, I suspect, our mind simply does not bow at the spectacle of the citizen who, despite strong ties of family and friendship, reveals their location to a tyrannical authority. Such an act of will may be monumental, but it is not majestic, and even seems to us peculiarly self-contained or blind. Can we attribute this response on our part to self-interest? No, the response seems to be the same even when we consider a case from history or fiction. Is it then merely an unconsidered reflex? No, Hume is right that our initial reaction to disobedience is usually discomfort. But we reflect further. The deep normative distress we feel when Germany's greatest moral philosopher defends the unalterable necessity of obedience to the state, and the exceptionless duty never to lie to conceal the location of a friend, is an impersonal and historical shudder. It arises from the full range of Humean faculties, developed through experience: reason, imagination, sense, sympathy, memory, and a feeling for one's place in history.

How different our reaction when we learn that Kant failed on one notable occasion to keep to his habit of regular afternoon walks - the afternoon he received Rousseau's Emile, and would not put it down. We might be less impressed by the iron will of Kant upon hearing this story, but we are more impressed by the man and his mind.

Let us conclude with a thought experiment using Kant's own division of the "three different relations that presentations have to the feeling of pleasure", namely, the agreeable, the beautiful, and the good, to understand our reactions and their normative force (CJ 210).

Suppose we had learned that Kant missed his afternoon walk only once, but not to read Emile - rather, to avoid a pesky visitor to town whom he knew to be lurking in wait for him with an embarrassing question he preferred not to answer. As a result we 
might like Kant better - he would be more amiable for showing this human tendency to indulge a desire to avoid an uncomfortable truth. But our self-conceit would not be struck down by this realization - instead, we would find it gratifying to our sense of ourselves that even Kant could be self-indulgent when it comes to allowing oneself to side-step an awkward truth. This we would find agreeable, but not in an altogether admiring way. Especially, the critic who finds Kantian moral rigorism excessive would smile inwardly, with perhaps a touch of condescension.

Suppose instead we had learned that he missed his afternoon walk on that one occasion in order to avoid spoiling the end of lovely afternoon tea with a visitor whom Kant rarely saw but personally admired. Then we would like the act, and also Kant, yet better. Moreover, we would like him and his act impersonally as well as personally - for someone to break from routine or personal resolution for such a reason shows a kind of gracefulness or beauty of gesture. Even those Kantian critics who find it gratifying to view him as a cold, "clockwork" Prussian would be taken a bit aback, and find a bit of appreciation of Kant creeping in.

But when we learn that in fact Kant missed his afternoon walk but once, in order to continue reading Rousseau's Emile Rousseau! whose unruly mind, scandalous conduct, and colorfully inconsistent prose contrast so sharply with Kant's, but whose insights we know nonetheless reached to the core of Kant's thinking - we like this because it possesses something of the sublime. And we like Kant better, impersonally as well as personally, for showing in a concrete but dramatically appropriate way just how attuned he was to the insights that awaited him in Rousseau, how capable he was of being displaced from the ruts the mind is wont to settle into. We here find in both Kant and his mind something good, something estimable in its own right. That afternoon's display of "mental attunement" is much more impressive than would be the strength of will, consistency, or resistance to inclination that Kant would have exhibited had he instead overcome the desire to continue reading Emile and maintained above all a resolve to take an afternoon walk each day, exactly at the same time. Thus does Kant's omission strike a bit at the self-conceit of critics who might attempt to look upon him with intellectual condescension as hermetic, narrowly moralistic, trapped within his own technical language and scheme of categories. For when we appreciate this story, we 
cannot help but feel, freely, a kind of admiration for Kant as an intellect. And thus does the experience of normativity combine force and freedom. ${ }^{23}$

\author{
Department of Philosophy \\ 2215 Angell Hall \\ University of Michigan \\ Ann Arbor \\ MI 48109-1003 \\ USA
}

23. Many colleagues and friends have helped me in developing ideas contained in this essay. Special thanks are due to Elizabeth Anderson, Paul Boghossian, Nomy Arpaly, Stephen Darwall, Allan Gibbard, David Hills, Mark Johnston, David Lewis, Donald Regan, Gideon Rosen, Michael Smith, David Velleman, and Kendall Walton, all whom have tried hard on a number of occasions to straighten out my thinking about normativity. I owe a particular debt to writings on normativity of Allan Gibbard and Christine Korsgaard, who have set out, from their own perspectives, much of the terrain I wander here. A long time ago, Nicholas Sturgeon made me realize I had to rethink Hume. And David Hills and Stephen Darwall deserve special thanks for patience in helping me to engage (insofar as I have!) with Kant's thought. Paul Guyer's writings and correspondence helped me find relevant passages in Kant. Jonathan Dancy gave me very useful comments on an earlier draft, and he and John Cottingham have been exceptionally considerate editors. 